\title{
Association between Adverse Childhood Experiences and Diagnosis of Cancer
}

\author{
Monique J. Brown ${ }^{1 *}$, Leroy R. Thacker ${ }^{2,3}$, Steven A. Cohen ${ }^{1}$
}

1 Department of Family Medicine and Population Health, Virginia Commonwealth University School of Medicine, Richmond, Virginia, United States of America, 2 Department of Biostatistics, Virginia Commonwealth University School of Medicine, Richmond, Virginia, United States of America, 3 Center for Clinical and Translational Research, Virginia Commonwealth University School of Medicine, Richmond, Virginia, United States of America

\begin{abstract}
Objective: Adverse childhood experiences (ACEs) are linked to multiple adverse health outcomes. This study examined the association between ACEs and cancer diagnosis.

Methods: Data from the 2010 Behavioral Risk Factor Surveillance System (BRFSS) survey were used. The BRFSS is the largest ongoing telephone health survey, conducted in all US states, the District of Columbia, Puerto Rico, Guam and the U.S. Virgin Islands, and provides data on a variety of health issues among the non-institutionalized adult population. Principal component analysis (PCA) was used to derive components for ACEs. Multivariable logistic regression models were used to provide adjusted odds ratios (OR) and 95\% confidence intervals (CI) for the association between ACE components and overall, childhood and adulthood cancer, adjusting for confounders such as age, gender, race/ethnicity, income, educational status, marital status, and insurance status.

Results: Approximately $62 \%$ of respondents reported being exposed to ACEs and about one in ten respondents reported ever having been diagnosed with cancer. Component 1, which had the sexual abuse variables with the highest weights, was significantly associated with adulthood cancer (adjusted OR: 1.21; 95\% Cl: 1.03-1.43).

Conclusion: The association between ACEs and adulthood cancer may be attributable to disease progression through association of ACEs with risk factors for other chronic diseases. More research should focus on the impact of sexual abuse ACEs and adverse health outcomes.
\end{abstract}

Citation: Brown MJ, Thacker LR, Cohen SA (2013) Association between Adverse Childhood Experiences and Diagnosis of Cancer. PLoS ONE 8(6): e65524. doi:10.1371/journal.pone.0065524

Editor: Manlio Vinciguerra, University College London, United Kingdom

Received January 4, 2013; Accepted April 21, 2013; Published June 11, 2013

Copyright: (c) 2013 Brown et al. This is an open-access article distributed under the terms of the Creative Commons Attribution License, which permits unrestricted use, distribution, and reproduction in any medium, provided the original author and source are credited.

Funding: Dr. Thacker's efforts on this research were supported in part by National Institutes of Health (NIH) Grant \# UL1TR00058 from the National Centers for Advancing Translational Sciences. The funders had no role in study design, data collection, and analysis, decision to publish, or preparation of the manuscript. No additional external funding was received for this study.

Competing Interests: The authors have declared that no competing interests exist.

* E-mail: brownmj7@vcu.edu

\section{Introduction}

Adverse childhood experiences (ACEs) represent a child's exposure to negative events, including emotional, physical and sexual abuse, domestic violence, absence of a parent because of divorce or separation, and a family/household member's mental illness, incarceration, and/or substance abuse $[1,2]$. Research has shown that majority of adults have experienced at least one ACE, [3] with prevalence estimates ranging from $65 \%$ to $87 \%$ [4,5]. The Centers for Disease Control and Prevention (CDC) has found that $59.4 \%$ of Behavioral Risk Factor Surveillance System (BRFSS) respondents in 2009 reported having at least one ACE, approximately $25 \%$ of adults reported experiencing $\geq 3$ ACEs and $8.7 \%$ reported $\geq 5$ ACEs [2]. These high prevalence estimates highlight the importance for additional efforts, locally, state-wide, and nationally, to help in the reduction and prevention of child maltreatment, and associated family dysfunction. There is also a need for services to treat outcomes, especially stress-related health illnesses, associated with ACEs [2], from childhood through adulthood.
Research has shown that ACEs are linked to multiple adverse health outcomes, and are interrelated rather than occurring independently [6]. ACEs have been linked to substance abuse [711], depression $[7,8,12,13]$, cardiovascular disease $[7,14]$, diabetes [7], cancer $[7,15,16]$, risky sexual behaviors [17-19], sexually transmitted infections $[7,8,19]$ suicidality $[7,8,13,17,18]$, and premature mortality in adulthood [17]. Researchers have suggested examining multiple ACEs allowing for a potential assessment of a graded relationship between these exposures and health outcomes [6]. However, exploring ACEs using principal component analysis (PCA), a more robust method, will account for the loading of each adverse experience. Using this strategy will allow for aggregation of ACE components that are likely to cluster together.

Stressful and/or traumatic experiences during childhood may also have neurodevelopmental impacts that persist over the lifespan [7]. The public health impact of ACEs has only been recently evaluated systematically through large epidemiologic efforts [20]. A strong relationship has been shown between stress and/or trauma during childhood, and smoking behavior [21,22] 
with a threefold increase in the risk of lung cancer for participants who had $\geq 6$ ACEs [15]. However, the increase in the risk of lung cancer could only be partially explained by the relationship between ACEs and smoking. Therefore, this finding suggests that the association between ACEs and cancer may be attributable to other mechanisms in which stressors and trauma during childhood negatively affect health [15]. In a prospective study, adverse events occurring between ages six and eight, and cumulative adversity from birth to age eight were found to be associated with inflammation at age ten [23].

While the link between ACEs and adverse health outcomes, including lung cancer, has been demonstrated, the association between ACEs and diagnosis of all cancers has not been examined. The main aims of this study were to: 1) Examine the association between ACEs and all cancers; and 2) Examine the association between ACEs, and childhood cancer and adulthood cancer. We hypothesize that we will see a positive association between ACEs, and overall, childhood and adulthood cancer. To our knowledge, this is the first study to examine the association between ACEs and all cancers, childhood and adulthood cancer using a populationbased sample.

\section{Methods}

\section{Ethics Statement}

The Virginia Commonwealth University Institutional Review Board provided a formal written waiver for the current study as publicly available, anonymous, secondary data were used. Verbal consent was provided to interviewers for the Behavioral Risk Factor Surveillance System survey [25].

\section{Data Source and Sample}

This cross-sectional study used data from the 2010 Behavioral Risk Factor Surveillance System (BRFSS) survey. The BRFSS is the largest ongoing telephone health survey, conducted in all US states, the District of Columbia, Puerto Rico, Guam and the U.S. Virgin Islands [24]. Established by the CDC, the BRFSS provides data on a variety of health issues among the non-institutionalized adult population (age 18 years and older). In addition to core questions that are asked by every state, there are optional modules that cover other health topics or ask more in-depth questions on a topic that was included among the core questions. The 2010 survey included an optional ACE module [25]. Wisconsin was the only state that also included the cancer survivorship module [25]. Respondents in Wisconsin who refused, or were not asked questions relating to ACEs and cancer diagnosis were not eligible $(\mathrm{n}=551)$. The resultant sample size was 4,230 .

\section{Operational Definition of Adverse Childhood Experiences}

The optional ACE module included questions about adverse, stressful and/or traumatic events experienced as a child (Table 1). We created three component scores of the ACEs using principal component analysis (PCA). The use of adverse events during childhood in research has shown to be dependable as the testretest reliability in the responses to questions about ACEs has been found to be good to excellent [26].

\section{Operational Definition of Cancer}

The Cancer Survivorship module, which was also optional, included several questions on cancer diagnosis and treatment. Cancer was selected as previous research has suggested a link between ACEs and different types of cancer [15,16]. Cancer diagnosis was defined by: 1) "Have you ever been told by a doctor, nurse, or other health professional that you had cancer?" which elicited a binary (yes/no) response; and 2) "At what age were you told that you had cancer?" Age of cancer diagnosis was then separated into 1-17 years (childhood cancer) [27-29] and 18 years or older (adulthood cancer). Self-reported data on cancer diagnosis has been shown to have high validity with moderate to excellent agreement to medical chart information, and has been shown to be useful for epidemiologic research $[27,28]$.

\section{Potential Confounders}

Potential confounders considered were either associated with ACEs or cancer diagnosis, as reported in the literature. In previous studies, sociodemographic variables were included as covariates [20]. Older age is a risk factor for cancer [29,30] and age was included as a continuous covariate. Sex and race/ethnicity were also included as covariates in the models as they are strong predictors for certain types of cancers. For example, aside from non-melanoma skin cancer, breast cancer is the most common cancer among women, and prostate cancer is the most common cancer among men [31-33]. From 1999 to 2008, White women had the highest breast cancer incidence rates while Black women had the highest mortality rates [34]. Men tend to have higher colorectal cancer incidence and mortality rates compared to women with Black men having higher colorectal cancer incidence and mortality rates compared to men of other racial/ethnic groups [35]. Income, educational level, and marital status have also been included in previous studies as a covariate examining the link between ACEs and adverse outcomes [15,20]. Socioeconomic status may partially explain the association of traumatic events during childhood with chronic illness [36]. Insurance status was also considered as a potential confounder as adverse experiences during childhood is linked to health [37], which is ultimately influenced by access to healthcare and insurance status.

\section{Analytic Approach}

All analyses considered the BRFSS complex multistage sampling strategy [38]. Weighted prevalence estimates were obtained for ACEs and cancer. Proc surveyfreq procedures were used for bivariate analyses to examine the association between age, gender, race/ethnicity, income, educational status, marital status and insurance status, and exposure to ACEs (Table 2). P values were used to determine statistically significant differences between exposure to overall ACEs and no exposure to ACEs.

PCA was used to obtain a score (Component 1) taking into consideration the shared information across the ACEs; and shape components (Components 2 and 3) that were independent of Component 1. We observed the component loading pattern (the correlation coefficients of the original variables with the components) (Table 3). Multivariable logistic regression models were used to provide adjusted odds ratios (OR) and 95\% confidence intervals (CI) for the association between the three principal components of ACEs and overall cancer, childhood cancer, and adulthood cancer adjusting for age, gender, race/ethnicity, income, educational status, marital status, and insurance status (Table 4). A variable was considered to be a potential confounder based on the literature review done a priori, as well as analyses shown in Table 2 comparing individuals exposed to ACEs to those not exposed to ACEs.

\section{Results}

\section{Weighted Prevalence Estimates}

The weighted prevalence of ACEs was $62.3 \%$. Approximately $10 \%$ of respondents reported having had a diagnosis of cancer, with $9.3 \%$ reporting their first diagnosis of cancer in adulthood 
Table 1. Types of Adverse Childhood Experiences, related BRFSS questions and operational definitions.

\begin{tabular}{|c|c|c|}
\hline Questions & Operational Definition & Abbreviation \\
\hline $\begin{array}{l}\text { 1) Did you live with anyone who was depressed, mentally } \\
\text { ill or suicidal? }\end{array}$ & No vs. Yes & DEPRS \\
\hline $\begin{array}{l}\text { 2) Did you live with anyone who was a problem drinker } \\
\text { or alcoholic? }\end{array}$ & No vs. Yes & DRINK \\
\hline $\begin{array}{l}\text { 3) Did you live with anyone who used illegal street drugs } \\
\text { or who abused prescription medications? }\end{array}$ & No vs. Yes & DRUGS \\
\hline $\begin{array}{l}\text { 4) Did you live with anyone who served time or was } \\
\text { sentenced to serve time in a prison, jail, or other } \\
\text { correctional facility? }\end{array}$ & No vs. Yes & PRISN \\
\hline 5) Were your parents separated or divorced? & No vs. Yes & DIVRC \\
\hline $\begin{array}{l}\text { 6) How often did your parents or adults in your home } \\
\text { ever slap, hit, kick, punch or beat each other up? }\end{array}$ & Never vs. At least once & PUNCH \\
\hline $\begin{array}{l}\text { 7) How often did a parent or adult in your home ever hit, } \\
\text { beat, kick, or physically hurt you in any way? Do not } \\
\text { include spanking. }\end{array}$ & Never vs. At least once & HURT \\
\hline $\begin{array}{l}\text { 8) How often did a parent or adult in your ho0me ever } \\
\text { swear at you, insult you, or put you down? }\end{array}$ & Never vs. At least once & SWEAR \\
\hline $\begin{array}{l}\text { 9) How often did anyone at least } 5 \text { years older than you or } \\
\text { an adult, ever touch you sexually? }\end{array}$ & Never vs. At least once & TOUCH \\
\hline $\begin{array}{l}\text { 10) How often did anyone at least } 5 \text { years older than you or } \\
\text { an adult, try to make you touch them sexually? }\end{array}$ & Never vs. At least once & TTHEM \\
\hline $\begin{array}{l}\text { 11) How often did anyone at least } 5 \text { years older than you } \\
\text { or an adult, force you to have sex? }\end{array}$ & Never vs. At least once & HVSEX \\
\hline
\end{tabular}

doi:10.1371/journal.pone.0065524.t001

and $0.2 \%$ reporting their first diagnosis of cancer during childhood. Among respondents who reported a diagnosis of cancer, $98.5 \%$ reported having their first diagnosis during adulthood (at age 18 or older).

\section{Distribution of Characteristics across Exposure Groups}

Table 2 shows the distribution of socio-demographic characteristics of BRFSS respondents by exposure and non-exposure to ACEs. There were statistically significant differences in the proportions of respondents who reported ACEs compared to those who did not by age, race/ethnicity, income, education, marital status, and insurance. More than half of the respondents who did not report exposure to ACEs were 50 years or older. Of the respondents who reported ACEs, $87.6 \%$ were White compared to $93.5 \%$ of the respondents who did not report ACEs. Among those respondents who reported ACEs, a higher percentage of Black, Hispanic or Other respondents reported ACEs compared to respondents in these racial/ethnic groups who did not report ACEs. There was no statistically significant difference by gender. Approximately a third of respondents who reported ACEs were high school graduates and just under a third of respondents had at least some college education.

\section{Component Loading Pattern}

Table 3 shows the ACE pattern derived from PCA. All the values for each ACE were positively correlated with Component 1. The sexual abuse variables (TOUCH, TTHEM and HVSEX) had the highest weights for Component 1. Variables that indicated ACEs that were not directed towards the child (DEPRS, DRINK, DRUGS, PRISN, DIVRC, and PUNCH) had the highest positive weights for Component 2; and the two variables that indicated psychological and physical abuse towards the child (HURT and SWEAR, respectively) had the highest positive weights for Component 3.
Association between ACEs and First Diagnosis of Cancer

Table 4 shows the association between ACEs and diagnosis of all cancers, childhood cancer and adulthood cancer. There were no statistically significant results using the unadjusted models. However, after adjusting for age, sex, race/ethnicity, income, education and marital status, Component 1 was significantly associated with being diagnosed with cancer in adulthood (adjusted OR: 1.21; 95\% CI: 1.03-1.43). Components 2 and 3 were not significantly associated with diagnosis of cancer.

\section{Discussion}

While many studies have reported on ACEs and specific types of cancer, to our knowledge, no study has reported on the association between ACEs and all cancers, differentiating between cancer in childhood and adulthood. The complex sampling scheme also provides population-based estimates. Among the respondents, approximately one in ten respondents reported ever having been diagnosed with cancer. The prevalence estimate of cancer derived from the current study of $10 \%$ is higher than the estimate of $4.2 \%$ derived from the National Cancer Institute (NCI) [39,40] and census population estimates [41]. Component 1, for which the sexual abuse variables had the highest weights, was significantly associated with cancer in adulthood.

This is the first study to examine adverse childhood experiences using PCA. By using PCA, we were able to use the data to derive three components of ACEs. Brown et al. (2010) found a positive association between ACEs and risk of lung cancer, which coincides with the findings in the current study. However, the current study considered prevalence of all cancers overall, in childhood and adulthood, in a cross-sectional study with a population-based sample while Brown et al. (2010) looked at incident lung cancer using a prospective study design [15]. 
Table 2. Distribution of socio-demographic characteristics of BRFSS respondents by Exposure to Adverse Childhood Experiences.

\begin{tabular}{|c|c|c|c|}
\hline \multirow[t]{4}{*}{ Confounders } & ACEs & No ACEs & P-value* \\
\hline & $\mathrm{N}=\mathbf{2 , 5 0 5}$ & $N=1,725$ & \\
\hline & $W N=2,463,391$ & $W N=1,490,356$ & \\
\hline & $\%$ & $\%$ & \\
\hline \multicolumn{4}{|l|}{ Age } \\
\hline $18-34$ & 36.6 & 20.1 & $<0.0001$ \\
\hline $35-49$ & 25.8 & 24.8 & \\
\hline $50+$ & 37.6 & 55.1 & \\
\hline \multicolumn{4}{|l|}{ Gender } \\
\hline Female & 50.5 & 50.6 & 0.9689 \\
\hline Male & 49.5 & 49.4 & \\
\hline \multicolumn{4}{|l|}{ Race/Ethnicity } \\
\hline White & 87.6 & 93.5 & 0.0001 \\
\hline Black & 3.5 & 1.6 & \\
\hline Hispanic & 3.0 & 0.8 & \\
\hline Other $^{a}$ & 5.9 & 4.2 & \\
\hline \multicolumn{4}{|l|}{ Income (Annual) } \\
\hline$<\$ 15,000$ & 5.4 & 2.1 & $<0.0001$ \\
\hline $\begin{array}{r}\$ 15,000- \\
<\$ 50,000\end{array}$ & 52.2 & 44.8 & \\
\hline$\$ 50,000+$ & 42.4 & 53.0 & \\
\hline \multicolumn{4}{|l|}{ Education $^{b}$} \\
\hline$<$ HS Graduate & 5.0 & 4.6 & 0.1437 \\
\hline HS Graduate & 32.9 & 29.2 & \\
\hline$>$ HS Graduate & 62.1 & 66.2 & \\
\hline \multicolumn{4}{|l|}{ Marital Status } \\
\hline Married & 58.8 & 69.5 & $<0.0001$ \\
\hline Not married & 41.2 & 30.5 & \\
\hline \multicolumn{4}{|l|}{ Insurance Status } \\
\hline Insured & 87.1 & 93.8 & $<0.0001$ \\
\hline Not insured & 12.9 & 6.2 & \\
\hline \multicolumn{4}{|c|}{$\begin{array}{l}\mathrm{N}=\text { Frequency; } \mathrm{WN}=\text { Weighted frequency. } \\
\text { *P-value shows differences between respondents exposed to ACEs and } \\
\text { unexposed to ACEs. } \\
\text { "The group "Other" contains respondents who identified themselves as } \\
\text { "Multiracial", "Other", "Native American/Alaska Native" and "Native Hawaiian/ } \\
\text { Other Pacific Islander". } \\
\text { bEducation categories: < High school graduate, High school graduate, > High } \\
\text { school graduate. } \\
\text { doi:10.1371/journal.pone.0065524.t002 }\end{array}$} \\
\hline
\end{tabular}

Evidence suggests that ACEs have been associated with risky sexual behaviors, [17-19] sexually transmitted infections, $[7,8,19]$ chronic diseases such as cancer, [15,16] obesity, [42] depression [7,8,12,13], and smoking [42,43]. Research has also shown that ACEs are associated with risk factors for chronic disease [15] such as chronic obstructive pulmonary disease [44], liver disease [4], and ischemic heart disease [14]. ACEs can be viewed as an initial exposure that may result in adverse health outcomes during adulthood. However, exposure to adversity during childhood is a likely source of, not only chronic but also acute stressors. [45] These acute stressors may alter fundamental biological functions, therefore, adversely impacting health, even
Table 3. Adverse Childhood Experiences Pattern derived by Principal Component Analysis.

\begin{tabular}{|c|c|c|c|c|c|}
\hline \multicolumn{2}{|c|}{ Component 1} & \multicolumn{2}{|c|}{ Component 2} & \multicolumn{2}{|c|}{ Component 3} \\
\hline ACE & Load & ACE & Load & ACE & Load \\
\hline TOUCH & 0.40 & DRUGS & 0.31 & SWEAR & 0.52 \\
\hline TTHEM & 0.40 & DRNK & 0.31 & HURT & 0.46 \\
\hline HVSEX & 0.38 & PUNCH & 0.29 & DIVRC & 0.37 \\
\hline HURT & 0.30 & PRISN & 0.28 & TOUCH & 0.03 \\
\hline PUNCH & 0.30 & DIVRC & 0.25 & DRUGS & -0.46 \\
\hline DRUGS & 0.29 & DEPRS & 0.20 & PRISN & -0.41 \\
\hline DRNK & 0.28 & HURT & 0.14 & PUNCH & -0.06 \\
\hline DEPRS & 0.26 & SWEAR & 0.07 & HURT & -0.05 \\
\hline DIVRC & 0.25 & TOUCH & -0.44 & SWEAR & -0.04 \\
\hline PRISN & 0.24 & TTHEM & -0.42 & TTHEM & -0.02 \\
\hline SWEAR & 0.07 & HVSEX & -0.39 & HVSEX & -0.01 \\
\hline
\end{tabular}

before the onset of adulthood. In utero exposure to adverse conditions can result in adverse health outcomes [46] throughout the life course. However, in the current study, we did not find an association between ACEs and childhood cancer. These findings suggest that ACEs may be related to adulthood cancer via alternate pathways as at present, we do not have biological models linking ACEs to cancer. One possible pathway is through the association of ACEs with risk factors for chronic diseases that may negatively affect general health and contribute to disease progression [15], which can predispose an individual for cancer in adulthood. However, more research is needed to explore this potential mechanism.

This study must be considered with limitations in mind. First, the study was cross-sectional. Based on the survey questions, we were not able to determine age of exposure to adverse childhood experiences. Therefore, it is possible that a diagnosis of cancer in childhood could have occurred before exposure to ACEs. However, since the majority of cancers were adulthood cancers $(98.5 \%)$, the ambiguity of temporal sequence would have only applied to $1.5 \%$ of the cancer cases in the overall category. It is also possible that there could have been underreporting of ACEs due to desirability bias, which would result in non-differential misclassification of the exposure. However, if this were the case, then the estimates produced would have been underestimates of the "true" association.

The study also had several strengths. We are able to obtain population-based estimates of the prevalence of cancer and exposure to ACEs using a comprehensive, nationally representative database. This is the first study to use PCA to assess the association of ACEs with an adverse health outcome, and the first study to examine ACEs and overall, childhood and adulthood cancer. The use of PCA also allowed for aggregation of variables that were likely to cluster together without relying on subjective construction of factors.

\section{Conclusions}

The results show an association between Component 1, for which the sexual abuse had the highest weights, and adulthood cancer. A reduction in ACEs, perhaps sexual abuse ACEs, could reduce adverse health outcomes, such as cancer. ACEs screening should be implemented during routine healthcare examinations for children and adults so as to help in identifying patients who 
Table 4. Multiple Logistic Regression of Principal Components of Adverse Childhood Experiences with Cancer Diagnosis in Adulthood.

\begin{tabular}{|c|c|c|c|c|c|c|}
\hline \multirow{3}{*}{ Component } & \multicolumn{2}{|l|}{ Overall } & \multicolumn{2}{|l|}{ Childhood } & \multicolumn{2}{|c|}{ Adulthood } \\
\hline & \multirow{2}{*}{$\frac{C^{C O R}}{(95 \% \mathrm{CI})}$} & \multirow{2}{*}{$\begin{array}{l}\text { aOR }^{b} \\
(95 \% \mathrm{Cl})\end{array}$} & \multirow{2}{*}{$\frac{\text { COR }^{a}}{(95 \% \mathrm{Cl})}$} & \multirow{2}{*}{$\begin{array}{l}\text { aOR }^{b} \\
(95 \% \mathrm{Cl})\end{array}$} & \multirow{2}{*}{$\frac{\text { COR }^{a}}{(95 \% \mathrm{CI})}$} & \multirow{2}{*}{$\begin{array}{l}\text { aOR }^{b} \\
(95 \% \mathrm{Cl})\end{array}$} \\
\hline & & & & & & \\
\hline \multirow[t]{2}{*}{ Component 1} & 1.02 & 1.15 & 1.35 & 0.75 & 1.02 & 1.21 \\
\hline & $(0.88-1.17)$ & $(0.97-1.37)$ & $(0.47-3.91)$ & $(0.48-1.18)$ & $(0.89-1.18)$ & $(1.03-1.43)$ \\
\hline \multirow[t]{2}{*}{ Component 2} & 0.90 & 1.06 & 1.05 & 0.88 & 0.86 & 1.03 \\
\hline & $(0.77-1.06)$ & $(0.86-1.31)$ & $(0.76-1.45)$ & $(0.43-1.81)$ & $(0.74-1.01)$ & $(0.83-1.29)$ \\
\hline \multirow[t]{2}{*}{ Component 3} & 1.10 & 0.95 & 1.35 & 2.52 & 1.10 & 0.93 \\
\hline & $(0.88-1.39)$ & $(0.76-1.18)$ & $(0.47-3.91)$ & $(0.47-13.4)$ & $(0.87-1.39)$ & $(0.74-1.17)$ \\
\hline
\end{tabular}

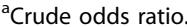

${ }^{\mathrm{b}}$ Adjusted odds ratio controlling for age, gender, race/ethnicity, income, educational status, marital status, and insurance status. doi:10.1371/journal.pone.0065524.t004

may be at risk for chronic illnesses. Future research should focus on sexual abuse ACEs and other adverse health outcomes to determine if individuals who experienced these specific types of ACEs would be at risk for other illnesses.

\section{References}

1. Anda RF, Butchart A, Felitti VJ, Brown DW (2010) Building a framework for global surveillance of the public health implications of adverse childhood experiences. Am J Prev Med 39: 93-98.

2. Centers for Disease Control and Prevention (CDC) (2010) Adverse childhood experiences reported by adults - five states, 2009. MMWR Morb Mortal Wkly Rep 59: 1609-1613.

3. Lanoue M, Graeber DA, Helitzer DL, Faecett J (2012) Negative Affect Predicts Adults' Ratings of the Current, but Not Childhood, Impact of Adverse Childhood Events. Community Ment Health J [Epub ahead of print].

4. Dong M, Anda RF, Dube SR, Giles WH, Felitti VJ (2003) The relationship of exposure to childhood sexual abuse to other forms of abuse, neglect, and household dysfunction during childhood. Child Abuse Negl 27: 625-639.

5. LaNoue M, Graeber D, de Hernandez BU, Warner TD, Helitzer DL (2012) Direct and indirect effects of childhood adversity on adult depression. Community Ment Health J 48: 187-192.

6. Dong M, Anda RF, Felitti VJ, Dube SR, Williamson DF, et al. (2004) The interrelatedness of multiple forms of childhood abuse, neglect, and household dysfunction. Child Abuse Negl 28: 771-784.

7. Felitti VJ, Anda RF, Nordenberg D, Williamson DF, Spitz AM, et al. (1998) Relationship of childhood abuse and household dysfunction to many of the leading causes of death in adults. The Adverse Childhood Experiences (ACE) Study. Am J Prev Med 14: 245-258.

8. Jewkes RK, Dunkle K, Nduna M, Jama PN, Puren A (2010) Associations between childhood adversity and depression, substance abuse and HIV and HSV2 incident infections in rural South African youth. Child Abuse Negl 34: 833-841.

9. Oladeji BD, Makanjuola VA, Gureje O (2010) Family-related adverse childhood experiences as risk factors for psychiatric disorders in Nigeria. Br J Psychiatry 196: $186-191$.

10. Strine TW, Dube SR, Edwards VJ, Prehn AW, Rasmussen S, et al. (2012) Associations between adverse childhood experiences, psychological distress, and adult alcohol problems. Am J Health Behav 36: 408-423.

11. Wu NS, Schairer LC, Dellor E, Grella C (2010) Childhood trauma and health outcomes in adults with comorbid substance abuse and mental health disorders. Addict Behav 35: 68-71.

12. Chapman DP, Whitfield CL, Felitti VJ, Dube SR, Edwards VJ, et al. (2004) Adverse childhood experiences and the risk of depressive disorders in adulthood. J Affect Disord 82: 217-225.

13. Pickles A, Aglan A, Collishaw S, Messer J, Rutter M, et al. (2010) Predictors of suicidality across the life span: the Isle of Wight study. Psychol Med 40: 14531466.

14. Dong M, Giles WH, Felitti VJ, Dube SR, Williams JE, et al. (2004) Insights into causal pathways for ischemic heart disease: adverse childhood experiences study. Circulation 110: 1761-1766.

15. Brown DW, Anda RF, Felitti VJ, Edwards VJ, Malarcher AM, et al. (2010) Adverse childhood experiences are associated with the risk of lung cancer: a prospective cohort study. BMC Public Health 10: 20.

\section{Author Contributions}

Conceived and designed the experiments: MJB LRT SAC. Performed the experiments: MJB LRT SAC. Analyzed the data: MJB LRT SAC. Contributed reagents/materials/analysis tools: MJB. Wrote the paper: MJB. Revised the manuscript: MJB LRT SAC.

16. Van der Meer LB, van Duijn E, Wolterbeek R, Tibben A (2012) Adverse childhood experiences of persons at risk for Huntington's disease or BRCA1/2 hereditary breast/ovarian cancer. Clin Genet 81: 18-23.

17. Brown DW, Anda RF (2009) Adverse childhood experiences: origins of behaviors that sustain the HIV epidemic. AIDS 23: 2231-2233.

18. Klein H, Elifson KW, Sterk CE (2007) Childhood neglect and adulthood involvement in HIV-related risk behaviors. Child Abuse Negl 31: 39-53.

19. Hillis SD, Anda RF, Felitti VJ, Nordenberg D, Marchbanks PA (2000) Adverse childhood experiences and sexually transmitted diseases in men and women: a retrospective study. Pediatrics 106: E11.

20. Vander Weg MW (2011) Adverse childhood experiences and cigarette smoking: the 2009 Arkansas and Louisiana Behavioral Risk Factor Surveillance Systems. Nicotine Tob Res 13: 616-622.

21. Anda RF, Croft JB, Felitti VJ, Nordenberg D, Giles WH, et al. (1999) Adverse childhood experiences and smoking during adolescence and adulthood. JAMA 282: $1652-1658$.

22. Jun HJ, Rich-Edwards JW, Boynton-Jarrett R, Austin SB, Frazier AL, et al. (2008) Child abuse and smoking among young women: the importance of severity, accumulation, and timing. J Adolesc Health 43: 55-63.

23. Slopen N, Kubzansky LD, McLaughlin KA, Koenen KC (2012) Childhood adversity and inflammatory processes in youth: A prospective study. Psychoneuroendocrinology.

24. Centers for Disease Control and Prevention (CDC) Behavioral Risk Factor Surveillance System website. Available: http://www.cdc.gov/brfss/index.htm. Accessed 2012 Aug 7.

25. Centers for Disease Control and Prevention (CDC) Behavioral Risk Factor Surveillance System: Questionnaires Modules by Category, 2010 website. Available: http://apps.nccd.cdc.gov/BRFSSModules/ModByCat. asp?Yr $=2010$. Accessed 2012 Aug 6 .

26. Dube SR, Williamson DF, Thompson T, Felitti VJ, Anda RF (2004) Assessing the reliability of retrospective reports of adverse childhood experiences among adult HMO members attending a primary care clinic. Child Abuse Negl 28: 729-737.

27. Gupta V, Gu K, Chen Z, Lu W, Shu XO, et al. (2011) Concordance of selfreported and medical chart information on cancer diagnosis and treatment. BMC Med Res Methodol 11: 72 .

28. Stavrou E, Vajdic CM, Loxton D, Pearson SA (2011) The validity of selfreported cancer diagnoses and factors associated with accurate reporting in a cohort of older Australian women. Cancer Epidemiol 35: e75-80.

29. Centers for Disease Control and Prevention (CDG) Breast Cancer Risk by Age website. Available: http://www.cdc.gov/cancer/breast/statistics/age.htm. Accessed 2012 Aug 7

30. Centers for Disease Control and Prevention (CDC) Prostate Cancer Risk by Age website. Available: http://www.cdc.gov/cancer/prostate/statistics/age.htm. Accessed 2012 Aug 7.

31. Centers for Disease Control and Prevention (CDC) Breast Cancer Statistics website. Available: http://www.cdc.gov/cancer/breast/statistics/index.htm. Accessed 2012 Aug 7. 
32. Centers for Disease Control and Prevention (CDC) Cancer Prevention and Control: Cancer Among Men website. Available: http://www.cdc.gov/cancer/ dcpc/data/men.htm. Accessed 2012 Aug 7.

33. Centers for Disease Control and Prevention (CDC) Cancer Prevention and Control: Cancer Among Women website. Available: http://www.cdc.gov/ cancer/dcpc/data/women.htm. Accessed 2012 Aug 7.

34. Centers for Disease Control and Prevention (CDC). Breast Cancer Rates by Race/Ethnicity website. Available: http://www.cdc.gov/cancer/breast/ statistics/race.htm. Accessed 2012 Aug 7.

35. Centers for Disease Control and Prevention (CDC) Colorectal (Colon) Cancer Rates by Race and Ethnicity website. Available: http://www.cdc.gov/cancer/ colorectal/statistics/race.htm. Accessed 2012 Aug 7.

36. Mock SE, Arai SM (2010) Childhood trauma and chronic illness in adulthood: mental health and socioeconomic status as explanatory factors and buffers. Front Psychol 1: 246.

37. Cambois E, Jusot F (2011) Contribution of lifelong adverse experiences to social health inequalities: findings from a population survey in France. Eur J Public Health 21: 667-673.

38. Centers for Disease Control and Prevention (CDC) Behavioral Risk Factor Surveillance System: 2010 BRFSS Overview website. Available: http://www. cdc.gov/brfss/technical_infodata/surveydata/2010.htm. Accessed 2012 Aug 14.
39. American Cancer Society. Cancer Prevalence: How Many People Have Cancer website. Available: http://www.cancer.org/Cancer/CancerBasics/cancerprevalence. Accessed 2012 Aug 14

40. National Cancer Institute website. Available: http://seer.cancer.gov/csr/1975_ 2008/. Accessed 2012 Aug 14.

41. U.S. Census Bureau, 2010 Census. Profile of General Population and Housing Characteristics: 2010 website. Available: http://factfinder2.census.gov/faces/ tableservices/jsf/pages/productview.xhtml?pid = DEC_10_DP_ DPDP1\&prodType = table. Accessed 2012 Aug 14 .

42. Dube SR, Cook ML, Edwards VJ (2010) Health-related outcomes of adverse childhood experiences in Texas, 2002. Prev Chronic Dis 7: A52.

43. Ford ES, Anda RF, Edwards VJ, Perry GS, Zhao G, et al. (2011) Adverse childhood experiences and smoking status in five states. Prev Med 53: 188-193.

44. Anda RF, Brown DW, Dube SR, Bremner JD, Felitti VJ, et al. (2008) Adverse childhood experiences and chronic obstructive pulmonary disease in adults. Am J Prev Med 34: 396-403.

45. Kelly-Irving M, Mabile L, Grosclaude P, Lang T, Delpierre C (2012) The embodiment of adverse childhood experiences and cancer development: potential biological mechanisms and pathways across the life course. Int J Public Health.

46. Barker DJ, Osmond C (1986) Infant mortality, childhood nutrition, and ischaemic heart disease in England and Wales. Lancet 1: 1077-1081. 